\title{
Phytochemical content and the potential of Punica granatum peel extracts as radical scavengers and dipeptidyl peptidase- 4 inhibitors
}

\author{
Lateef A. Malik Ali H. Ad'hiah* Ghazi M. Aziz
}

Biotechnology Department/ College of Science/ University of Baghdad

* Tropical-Biological Research Unit/ College of Science/ University of Baghdad E-mail: lateef230@gmail.com

\begin{abstract}
Background: Natural products of herbal medicines and their secondary metabolites have been suggested to treat T2DM and they may have the potential as DPP-4 inhibitors.

Objective: This study was conducted to estimate the phytochemical content , radical scavenging activity (RSA) and DPP-4 (dipeptidyl peptidase-4) relative inhibition activity (RIA) of different extracts of Punica granatum peel.

Material and Methods: Fruit peel of pomegranate plant Punica granatum were subjected to extraction with four solvents (distilled water(AQ), $80 \%$ methanol(ME), $80 \%$ acetone(AC) and a mixed solvent(MX) that included methanol, ethanol, acetone and n-butanol at proportions (7:1:1:1), respectively. Yielded extracts were phytochemically analyzed for total polyphenols (TP), flavonoids (TF) and HPLC analysis. The DPPH (2,2-diphenyl-1-picrylhydrazyl) radical scavenging activity (RSA) and DPP-4 (dipeptidyl peptidase-4) relative inhibition activity (RIA) were also assessed for each extract.

Results: The results showed that acetone solvent (AC) extract of fruit peel of Punica granatum recorded the highest content of TP and TF $(159.9 \pm 1.0 \mathrm{mg}$ Gallic acid equivalent/g dry mass) and (7.6 $\pm 0.2 \mathrm{mg}$ catechin equivalent/g dry mass, respectively) . Mixture extract (MX) was showed the highest antioxidant activity of $(54.7 \pm 0.9 \%$ RSA $)$. While methanol extract (ME) recorded the highest DPP-4 RIA $(47.1 \pm 1.5 \%)$. HPLC analysis showed the presence of Gallic acid, Tannic acid, Ellagic acid and B carboxylic acid at concentrations of $(94.61,130.14,528.46$ and $159.64 \mathrm{ug} / \mathrm{ml}$, respectively). Conclusion: The importance of natural products as radical scavengers and DPP-4 inhibitors is encouraged, and such biological effects were dependent on the plant species and the solvent of extraction. Punica granatum mixture extract was suggested to have a prominent RSA, while methanol extraction of Punica granatum peels are recommended to be a target for investigations involved in the development of anti-T2DM and anti-cancer therapies.
\end{abstract}

Keywords: Punica granatum, peels, total polyphenol, flavonoids, HPLC, DPPH, DPP-4, inhibition.

\section{Introduction}

Type 2 Diabetes mellitus (T2DM) is a global disease and recent estimates have revealed that around $10 \%$ of adults are diabetic, and $90 \%$ of whom are grouped under T2DM (1). It is a progressive chronic metabolic syndrome that is hallmarked by hyperglycemia due to a defect in insulin secretion, insulin action, or betacell impairment (2). The disease is complex in terms of etiology and pathogenesis, and several metabolic inflammatory signaling pathways are triggered by the established hyperglycemia. The consequence is cell death (apoptosis) and diabetic complications, which include nephropathy, retinopathy and cardiovascular diseases (3). Oxidative damages mediated by highly reactive free radicals have been depicted to play an important role in these complications, and interplay between diabetes and oxidative stress has been suggested (4).

Hyperglycemia in T2DM is controlled by different oral hypoglycemic agents. They are classified as enhancers of insulin secretion (sulfonylureas and glinides) or insulin sensitivity (metformin and the thiazolidinediones). A further group includes inhibitors of intestinal carbohydrate absorption (alphaglucosidase inhibitors) (5). However, these agents have a complex mechanism of action, and they are associated with some adverse effects (hypoglycemia, weight gain, gastrointestinal disturbance, lactic acidosis and fluid retention) (6). Over the last decade, oral hypoglycemic agents that inhibit the enzyme dipeptidyl peptidase-4 (DPP-4) have emerged as an effective and promising therapeutic strategy for the management of T2DM (7).

DPP-4 is a serine protease that cleaves N-terminal dipeptides from polypeptides, and by such pathway, it regulates the bioactivity of many peptides including the two incretin hormones glucagon like peptide -1 (GLP-1) and glucose dependent insulinotropic polypeptide (GIP), which are major regulators of postprandial insulin secretion (8). GLP-1 has been suggested to have trophic effects on pancreatic $\beta$-cells and has been reported to inhibit glucagon release. Similarly, GIP stimulates insulin secretion in a glucose-dependent manner, and in addition to its insulinotropic effect, it also elicits glucagon release (9). In T2DM, a decrease in the incretin effect and rapid degradation of short lived GLP-I and GIP have been reported due to their rapid inactivation by DPP-4, and consequently, GLP-1 and GIP are no longer available in the active form 
(10). Therefore, an efficient therapy with DPP-4 inhibitors can inactivate the enzyme and prevent the cleavage of GLP-1 and GIP and prolong their half-life and biological activity (7).

Several DPP-4 inhibitors have recently been approved, and these medicines have been reported to have the potential of lowering blood glucose and glycosylated hemoglobin type $\mathrm{A} 1 \mathrm{C}\left(\mathrm{HBA}_{\mathrm{lc}}\right)$ levels and to improve glucose tolerance in T2DM patients (11). However, natural products of herbal medicines and their secondary metabolites have been increasingly suggested to treat T2DM and they may have the potential as DPP-4 inhibitors (12); for instance, it has been reported that naringin, a flavanone glycoside of a plant origin, shows a potent inhibiting effect on serum level of DPP-4 (13). Furthermore, plants have been widely recognized as a cardinal source of antioxidant and radical scavenger agents, with increasing evidence that supports their health-promoting properties (14).

Accordingly, the present study was designed to determine the in vitro DPP-4 inhibitory potential of peel of Punica granatum extracted by different solvents. Besides that, phytochemical screening (polyphenols and flavonoids), and antioxidant activity were also assessed. The selection of this plant was based on their applications in traditional medicine in Iraq.

\section{Material and methods \\ .Reagents}

DPP-4 inhibitor screening kit was purchased from Sigma-Aldrich (Germany). Gallic acid and catechin standards, Folin-Ciocalteu, aluminum trichloride, sodium carbonate, sodium hydroxide, sodium nitrite and DPPH (2,2-diphenyl-1-picrylhydrazyl) were products of Merck company (Germany). Methanol, ethanol, acetone and n-butanol were products of BDH (UK).

\section{.Raw plant materials}

Punica granatum was purchased from a local market(June, 2017) in Nasiriyah, a city located $375 \mathrm{~km}$ south the capital Baghdad, and the peels were used, respectively.. It was taxonomically identified by the herbarium staff at the Faculty of Agriculture and Marshes (Thi-Qar University).

\section{.Preparation of plant extracts}

Pomegranate peels were rinsed with tap-water, and then air-dried in a hot-air oven at $40^{\circ} \mathrm{C}$ for 72 hours. Dried plant parts were pulverized with stainless steel electric grinder, and the powder was stored in a dark tight-sealed glass container at room temperature $\left(20-25^{\circ} \mathrm{C}\right)$. Three grams of each powder were extracted with $30 \mathrm{ml}$ of a solvent. Four solvents were used; distilled water , 80\% methanol (v/v),80\% acetone (v/v) and a mixed solvent (methanol:ethanol:acetone:n-butanol at proportions 7:1:1:1)(MX). Accordingly, four extracts were yielded; four extracts (AQ, ME, AC and MX, respectively). The plant powder was mixed with the solvent in $50 \mathrm{ml}$ conical flask for 24 hours using a magnetic stirrer at room temperature. The obtained solution was centrifuged (3000 rpm for 15 minutes) and the supernatant was collected in petri-dishes, which were transferred to a hot-air oven $\left(40^{\circ} \mathrm{C}\right)$ till the solvent was evaporated. The resulting plant extract layer was scraped from the surface of petri dishes, collected, weighted and kept in a dark tight-sealed glass container, which was stored at $-20^{\circ} \mathrm{C}$ until experimental use.

\section{.Determination of total polyphenols}

Total polyphenols (TP) were determined by the Folin-Ciocalteu (F-C) assay (15). Briefly, $0.5 \mathrm{~mL}$ of each extract $(1.0 \mathrm{mg} / \mathrm{mL})$ or Gallic acid aqueous solutions $(5,10,15,20$ and $25 \mathrm{mg} / \mathrm{mL})$ was mixed with $2.5 \mathrm{~mL}$ of F-C reagent. Regarding blank, $0.5 \mathrm{ml}$ of methanol $95 \%$ was used. A minute later, $2.5 \mathrm{~mL}$ of $20 \%$ sodium carbonate $\left(\mathrm{Na}_{2} \mathrm{CO}_{3}\right)$ solution (w/v) was added, and the mixture was allowed to stand for a further 30 minutes in the dark, and the absorbance was measured at a wavelength of 760nm. A standard curve was plotted and TP were expressed as mg Gallic acid equivalent per gram of dry mass (mg GE/g DM). Figure (1). 


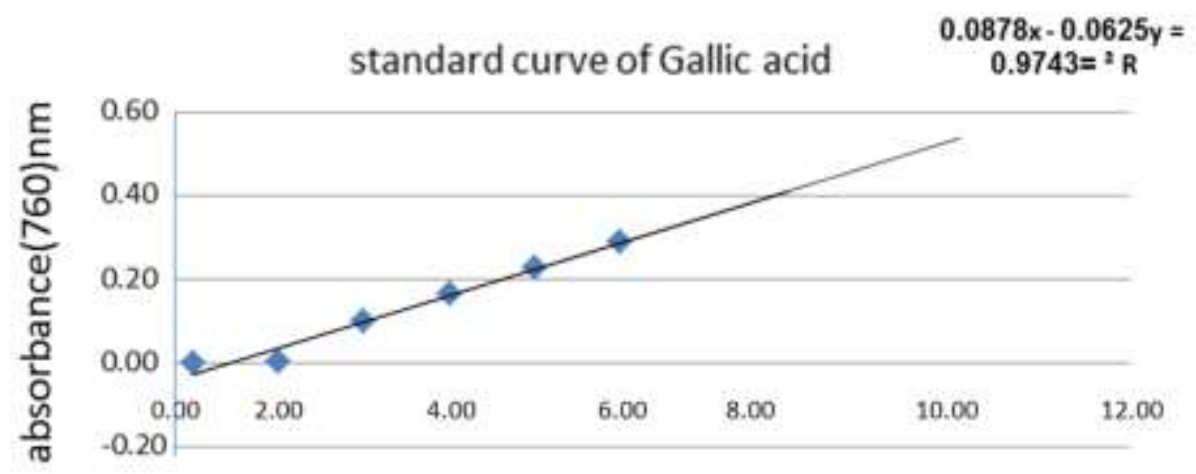

concentration of gallic acid $(\mathrm{mg} / \mathrm{ml})$

Figure (1): standard curve of Gallic acid

\section{.Determination of total flavonoids}

Total flavonoids (TF) were estimated by a colorimetric method using aluminium chloride $\left(\mathrm{AlCl}_{3}\right)$ and sodium hydroxide $(\mathrm{NaOH})(16)$. Briefly, $0.05 \mathrm{~mL}$ of either $1.0 \mathrm{mg} / \mathrm{mL}$ of each extract or catechin standards $(10,20,30,40,50$ and $60 \mathrm{mg} / \mathrm{mL})$ were mixed with $2.0 \mathrm{~mL}$ of distilled water. Regarding blank, $0.05 \mathrm{ml}$ of methanol $95 \%$ were used. Then, $0.15 \mathrm{~mL}$ of $150 \mathrm{~g} / \mathrm{L}$ sodium nitrite $\left(\mathrm{NaNO}_{2}\right)$ solution, and $0.15 \mathrm{~mL}$ of 100 $\mathrm{g} / \mathrm{L} \mathrm{AlCl}_{3} \cdot 6 \mathrm{H}_{2} \mathrm{O}$ solution. After 6 minutes, $2.0 \mathrm{~mL}$ of $\mathrm{NaOH}$ solution $(\mathrm{mol} / \mathrm{L}$ ) was added and the volume was made-up to $5.0 \mathrm{~mL}$ with distilled water. The mixture was allowed to stand in dark for 15 minutes, and the absorbance was measured at a wavelength of $510 \mathrm{~nm}$. A standard curve was plotted and TF were expressed as $\mathrm{mg}$ catechin equivalent per gram of dry mass ( $\mathrm{mg} \mathrm{CE} / \mathrm{g} \mathrm{DM}$ ).

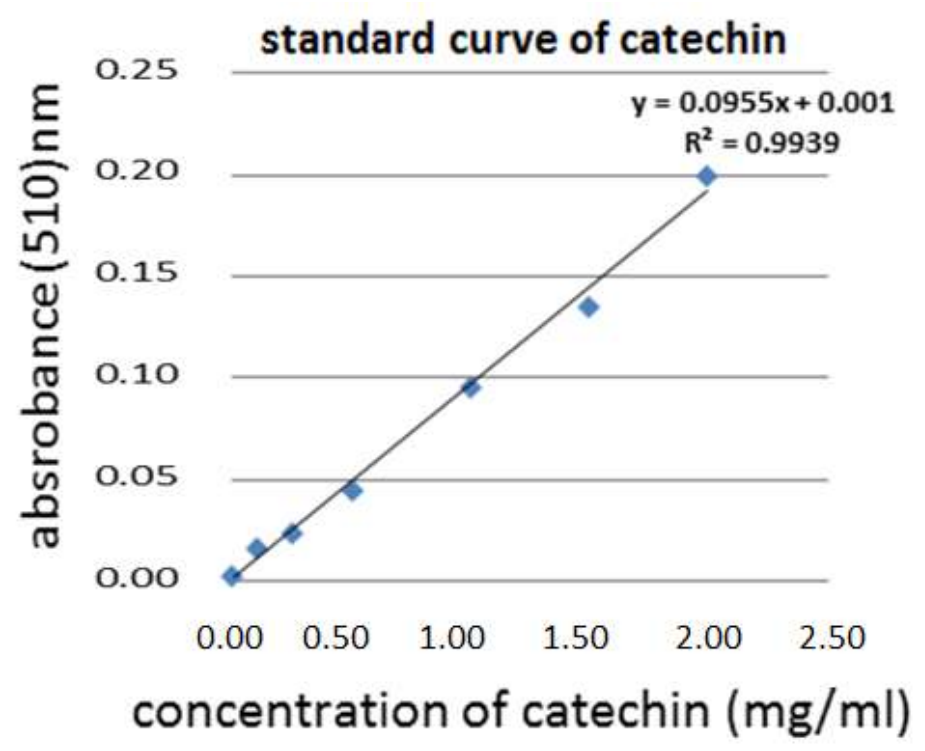

Figure (2): standard curve of catechin

\section{.Antioxidant activity}

The DPPH radical-scavenging activity (RSA) was adopted to assess the antioxidant activity of extracts in 96-well microplates, as previously described with a slight modification (17). Briefly, two reaction wells were assigned; in the first well, $100 \mu \mathrm{l}$ of plant extract $(500 \mu \mathrm{g} / \mathrm{ml})$ was added (sample-blank), while in the second well, $100 \mu \mathrm{l}$ of $0.2 \mathrm{mmol} / \mathrm{L}$ DPPH solution in $95 \%$ methanol solution was added together with the plant extract as in the first well (sample+DPPH). Solvent $(100 \mu 1$ of 95\% methanol) and DPPH (100 $\mu 1$ of $0.2 \mathrm{mmol} / \mathrm{L} \mathrm{DPPH}$ ) were also included in a further two wells. Then, the microplate was incubated for 30 minutes in the dark at room temperature, and the absorbance was recorded for each well at $517 \mathrm{~nm}$ 
wavelength using a microplate reader (ELx800 BioTek Instruments Inc .USA). The percentage of DPPH RSA was calculated using the following equation:

$$
\text { \% DPPH RSA }=((\mathrm{A}-\mathrm{B}) /(\mathrm{C}-\mathrm{D})) \times 100
$$

Where A: sample+DPPH absorbance, B: sample-blank absorbance,

C: DPPH absorbance, D: solvent absorbance

\section{.DPP-4 inhibition screening assay}

The DPP-4 inhibition screening kit (Catalog Number MAK203, Sigma-Aldrich, Germany) was used to assess the DPP-4-inhibitory effect of four extracts. The principle of assessment is based on measuring the DPP-4 activity by cleaving the substrate to yield a fluorescent product $\left(\lambda_{\mathrm{ex}}=360 \mathrm{~nm} / \lambda_{\mathrm{em}}=460 \mathrm{~nm}\right)$, which is proportional to the enzymatic activity present in the test sample. The effectiveness of the tested inhibitors was compared with a standard DPP-4 inhibitor (sitagliptin) provided with the kit. The instructions of manufacturer were followed, and the DPP-4-inhibition activity of extracts was given as percentage of relative inhibition (relative inhibition activity; RIA).

\section{.HPLC sample preparation}

Fifty mg of crude of pomegranate methanol extract(the highest DPP4 inhibitory potent) were mixed and dissolved in $10 \mathrm{ml}$ of (80:20) V/V Methanol: water), The extract was subjected to ultra-sonication (Branson sonifier, USA) at $\% 60$ duty cycles for $25 \mathrm{~min}$ at $25^{\circ} \mathrm{C}$ followed by centrifugation at $7,500 \mathrm{rpm}$ for $15 \mathrm{~min}$. The clear supernatant of each sample was subjected to charcoal treatment to remove pigments prior to evaporation under vacuum (Buchi Rotavapor Re Type). Dried samples were re-suspended in $1.0 \mathrm{ml}$ HPLC grade methanol by vortexing, the mixture were passed through 2.5 um disposable filter, and stored at $4^{\circ} \mathrm{C}$ for further analysis ,then $20 \mathrm{ul}$ of the sample were injected into HPLC system according the optimum separation condition previously fixed with authentic pure standard ( from Sigma U.K). (18).

The separation done by using liquid chromatography Shimadzu 10AV-LC equipped with binary delivery pump model LC-10A Shimadzu, while eluted peaks were monitored by UV -Vis 10 A-SPD spectrophotometer. Under the optimum condition, FLC (Fast Liquid Chromatographic) Phenomenex C-18,3 um particle size ( 50 x $2.0 \mathrm{~mm}$ I.D) column was used. Mobile phase: linear gradient of $0.1 \%$ formic acid as solvent and solvent $\mathrm{B}$ was $(6: 3: 1)(\mathrm{v} / \mathrm{v})$ of acetonitrile : methanol: $0.1 \%$ formic acid ,respectively. A gradient program from $0 \% \mathrm{~B}$ to $100 \% \mathrm{~B}$ for 8 minutes and flow rate of $1.2 \mathrm{ml} / \mathrm{min}$ was performed .Elution was detected in UV $280 \mathrm{~nm}$ at $25^{\circ} \mathrm{C}(18)$.

\section{Calculation}

Conce. of sample ug/ml $=($ Area of sample $/$ Area of standard $) *($ conce. of standard $) \mathrm{x}$ dilution Factor

\section{.Experimental Design and Statistical analysis}

An in vitro study was designed to evaluate the potential of some plants (given in section raw plant materials) as DPP-4 inhibitors after their extraction with different solvents. Data were given as mean \pm standard deviation (SD) of duplicate assessments, and significant difference between means was assessed by Duncan's multiple range test, in which a $p$-value of $\leq 0.01$ was considered significant. Pearson bivariate analysis was also employed to estimate the correlation between investigated parameters. The SPSS software (version 13.0) was used to carry out these analyses.

\section{Results}

\section{.Phytochemical contents, DPPH RSA and DDP-4 RIA (Table 1)}

Phytochemical analysis of TP and TF content revealed significant variations between the analyzed plant extracts. For TP, the acetone extract of $P$. granatum peels showed the highest content $(159.9 \pm 0.4 \mathrm{mg} \mathrm{GE} / \mathrm{g}$ $\mathrm{DM})$, while a lowest content was recorded in methanol (101.2 $\pm 1.0 \mathrm{mg} \mathrm{GE} / \mathrm{g} \mathrm{DM})$. In the case of TF, the acetone extract dominated the highest content $(7.6 \pm 0.2 \mathrm{mg} \mathrm{CE} / \mathrm{g} \mathrm{DM})$, which was counteracted by a lowest content $(3.6 \pm 0.1 \mathrm{mg} \mathrm{CE} / \mathrm{g} \mathrm{DM})$ in the aqueous extract.

The DPPH RSA was also subjected to a significant variation between extracts, and mixture extract was remarkable in scoring $54.7 \pm 0.9 \%$ RSA. While the lowest RSA was recorded in the P. granatum aqueous extract $(30.5 \pm 2.1 \%)$. The antioxidant activity of pomegranate fruit peels was also evaluated in vitro, and the results showed that the reducing power of methanolic extract was more potent than either aqueous extract or ether extract. The radical scavenging potent of methanol extract was also greater than that of $\alpha$ catechin and this was due to their richness in phenolic compounds(19). 
The assessment of DDP-4 RIA revealed a range of a significant variation that was related to the solvent of extraction. (AQ, AC and ME) were the high of list (43.1 $\pm 1.4,44.0 \pm 0.9$ and $47.1 \pm 1.5 \%$, respectively). Whereas, MX extract recorded the lowest DDP-4 RIA, which was $28.7 \pm 0.9 \%$.

Additionally, a study investigated the effect of P. granatum peel extract that was administrated orally to alloxan-induced diabetic rats suggested that the extract exhibited an anti-diabetic effect by lowering blood glucose levels and increasing GLP-1R mRNA level in intestinal cells via the inhibitory potent on DPP-4 (20).

Table (1): Phytochemical contents and DPPH radical scavenging and DDP-4 relative inhibition activities of pomegranate extracts

\begin{tabular}{|c|c|c|c|c|c|}
\hline plant & solvents & $\begin{array}{l}\text { Polyphenols } \\
\text { (mg GE/g } \\
\text { DM) }\end{array}$ & $\begin{array}{l}\text { Flavonoids } \\
\text { (mg CE/g DM) }\end{array}$ & $\begin{array}{l}\text { DPPH RSA } \\
(\%)\end{array}$ & $\begin{array}{l}\text { DPP-4 RIA } \\
(\%)\end{array}$ \\
\hline \multirow{4}{*}{$\begin{array}{l}\text { Punica } \\
\text { granatum } \\
\text { (peel) }\end{array}$} & (aqueous) & $154.7 \pm 1.2$ & $3.6 \pm 0.1$ & $30.5 \pm 2.1 \%$ & $43.1 \pm 1.4 \%$ \\
\hline & (methanol) & $101.2 \pm 1.0$ & $4.8 \pm 0.2$ & $53.6 \pm 0.6 \%$ & $47.1 \pm 1.5 \%$ \\
\hline & (acetone) & $159.9 \pm 0.4$ & $7.6 \pm 0.2$ & $52.0 \pm 0.1 \%$ & $44.0 \pm 0.9 \%$ \\
\hline & (mixture) & $154.3 \pm 1.5$ & $4.3 \pm 0.2$ & $54.7 \pm 0.9 \%$ & $28.7 \pm 0.9 \%$ \\
\hline
\end{tabular}

\section{.HPLC analysis Table (2)}

HPLC analysis for methanol extract of pomegranate peel (the highest DPP4 inhibitory potent) showed the presence of many phenolic and flavonoid compounds. Among them, Ellagic acid was found dominantly in concentration of $528.46 \mathrm{ug} / \mathrm{ml}$. while B carboxylic acid, tannic acid and gallic acid were found in concentrations of (159.64, 130.14 and 94.61, respectively). Figure (3).

Table (2): HPLC analysis show the phytochemical contents of methanol extract of pomegranate peel

\begin{tabular}{lccccc}
\hline & Subjects & Retention time(min) & $\begin{array}{c}\text { Area of } \\
\text { standard } \\
(\mathbf{u} \text { volt })\end{array}$ & $\begin{array}{c}\text { Area of sample } \\
(\mathbf{u} \text { volt })\end{array}$ & $\begin{array}{c}\text { Concentration } \\
(\mathrm{ug} / \mathrm{ml})\end{array}$ \\
\cline { 3 - 6 } 1 & Gallic acid & 1.98 & $\mathbf{8 3 0 7 4}$ & 31438 & 94.61 \\
2 & Tannic acid & 3.302 & 71471 & 37205 & 130.14 \\
3 & Ellagic acid & 4.22 & 70740 & 149534 & 528.46 \\
4 & B Carboxylic acid & 5.15 & 67703 & 43233 & 159.64 \\
\hline
\end{tabular}




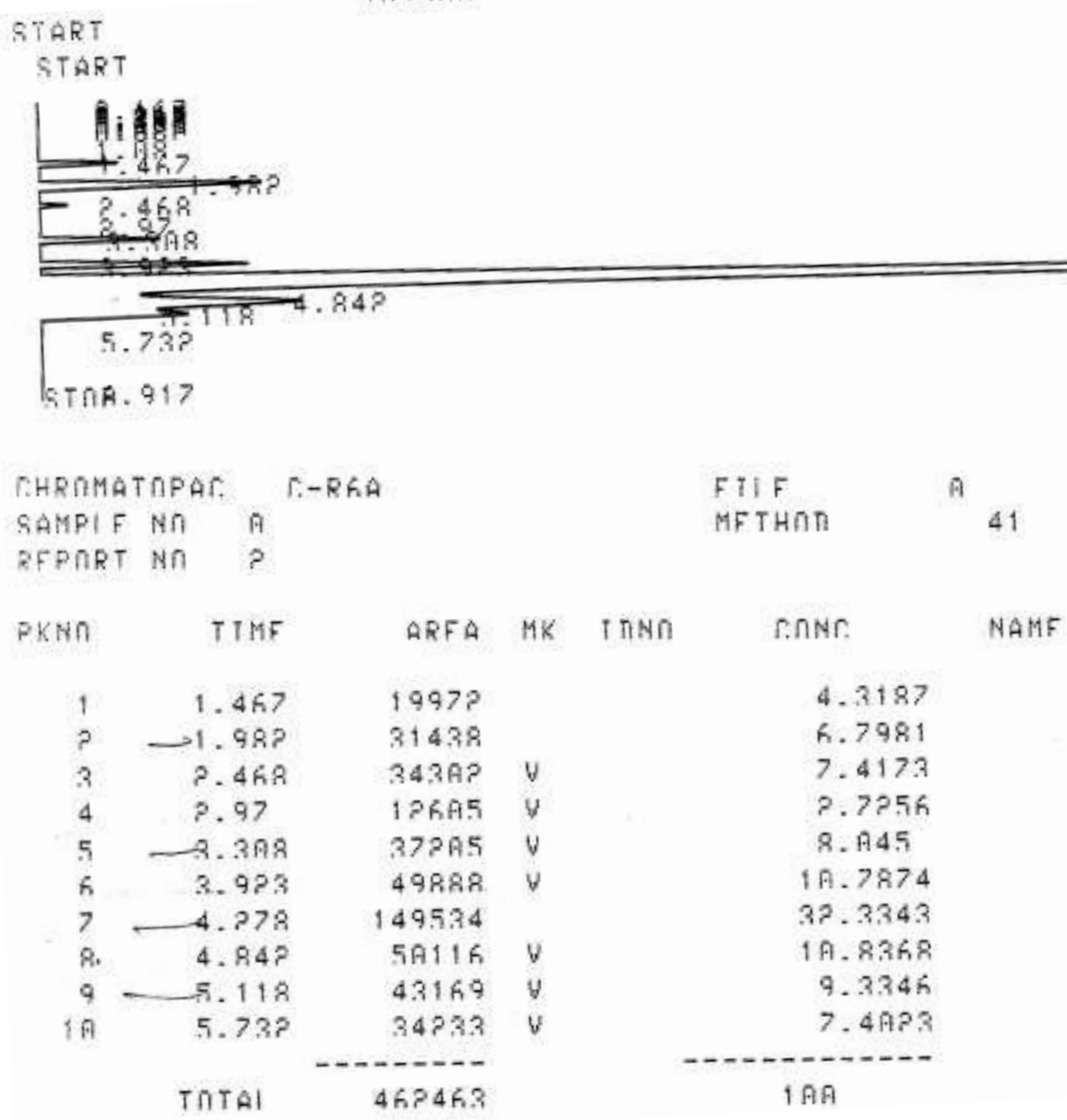

Figure (3): HPLC analysis sheet show the phytochemical contents of methanol extract of pomegranate peel

.Correlation between the Forthcoming Parameter

Pearson bivariate analysis showed that there was no correlation between phytochemicals of $P$. granatum peel extracts and DPPH RSA and DPP-4RIA.

Table (3): Pearson bivariate correlation between phytochemical contents and DPPH radical scavenging and DDP-4 relative inhibition activities of methanolic extract of pomegranate peels

\begin{tabular}{lcccc}
\hline Parameter & Polyphenol & Flavonoid & DPPH RSA & DPP-4 RIA \\
\hline Polyphenols & 1.000 & & & \\
Flavonoids & 0.183 & 1.000 & & \\
DPPH RSA & -0.303 & 0.496 & 1.000 & 1.000 \\
\hline DPP-4 RIA & -0.472 & 0.272 & -0.245 & \\
\hline
\end{tabular}

DPPH: 2,2-diphenyl-1-picrylhydrazyl, RSA: Radical scavenging activity, DPP-4: Dipeptidyl peptidase-4, RIA: Relative inhibition activity. *Correlation is significant at $p$-value $\leq 0.05$ (2-tailed). **Correlation is significant at $p$-value $\leq 0.01$ (2-tailed). 


\section{Conclusion}

Results of present study suggest the great value of $P$. granatum peel extract use in phytotherapy. Based on this information, it could be concluded that peels of this plant is natural sources of antioxidant and anticancer of high importance compounds like ellagic acid, B carboxylic acid ,tannic acid and gallic acid depending on type and polarity of extraction solvents.

It is noticed that the highest concentration of phenolic and flavonoid compounds in the extracts were obtained using acetone solvent, while the methanolic extract manifested greater power of extraction for DPP4 inhibition.and antioxidant activity (18) .

Further studies of this plant species are recommended to carry out in vivo studies of its medicinal active components in order to prepare a natural pharmaceutical product of high value.

\section{Conflict of interest}

The authors declare that there is no conflict of interest.

\section{Acknowledgments}

The authors appreciate the cooperation of the herbarium staff at the Faculty of Agriculture and Marshes (Thi-Qar University).

\section{References}

1. Zheng Y, Ley SH, Hu FB. "Global aetiology and epidemiology of type 2 diabetes mellitus and its complications," Nat. Rev. Endocrinol. (2017); 14( 2) : 88-98.

2. American Diabetes Association, "Diagnosis and classification of diabetes mellitus," Diabetes Care. (2009); 31(1) : S62-S67.

3. Hameed I, Masoodi SR, Mir SA, Nabi M, Ghazanfar K, Ganai BA. "Type 2 diabetes mellitus: from a metabolic disorder to an inflammatory condition.," World J. Diabetes. (2015);6 (4): 598-612.

4.Asmat U, Abad K, Ismail K. "Diabetes mellitus and oxidative stress-A concise review.," Saudi Pharm. J. SPJ Off. Publ. Saudi Pharm. Soc.( 2016); 24 ( 5): 547-553.

5. Levetan C. "Oral antidiabetic agents in type 2 diabetes.," Curr. Med. Res. Opin. (2007);23(4): 945-952.

6. Tara J, et al.. "Adverse Effects of Oral Hypoglycemic Agents and Adherence to them among Patients with Type 2 Diabetes Mellitus in Nepal," Journal of Lumbini Medical College. J. Lumbini. Med. Coll.(2017); 5 (1): 34-40.

7. Mulvihill EE. "Dipeptidyl peptidase inhibitor therapy in type 2 diabetes: control of the incretin axis and regulation of postprandial glucose and lipid metabolism," Peptides.(2018);100: 158-164.

8. Röhrborn D, Wronkowitz N, Eckel J. "DPP4 in diabetes," Front. Immunol.( 2015); (6 )386.

9. Lacroix IME, Li-Chan ECY. "Food-derived dipeptidyl-peptidase IV inhibitors as a potential approach for glycemic regulation - Current knowledge and future research considerations," Trends Food Sci. Technol.(2016); 54:1-16.

10. Papaetis GS. "Incretin-based therapies in prediabetes: Current evidence and future perspectives, "World J. Diabetes.(2014); 5(6):817.

11. Ji $\mathrm{X}$,et al.. "Design, synthesis and biological evaluation of 4-fluoropyrrolidine-2-carbonitrile and octahydrocyclopenta(b)pyrrole-2-carbonitrile derivatives as dipeptidyl peptidase IV inhibitors," Eur. J. Med. Chem(2014);86: 242-256.

12. $\mathrm{Xu} \mathrm{L,} \mathrm{Li} \mathrm{Y,} \mathrm{Dai} \mathrm{Y,} \mathrm{Peng} \mathrm{J.} \mathrm{"Natural} \mathrm{products} \mathrm{for} \mathrm{the} \mathrm{treatment} \mathrm{of} \mathrm{type} 2$ diabetes mellitus: Pharmacology and mechanisms," Pharmacol. Res. (2018).

13. Parmar HS, et al. "DPP-IV inhibitory potential of naringin: an in silico, in vitro and in vivo study," Diabetes Res. Clin. Pract. (2012); 97( 1): 105-111.

14. Guesmi F, Ben Hadj AS, Landoulsi A. "Investigation of extracts from Tunisian ethnomedicinal plants as antioxidants, cytotoxins, and antimicrobials.," Biomed. Environ. Sci. (2017);30(11): 811-824.

15. Singleton VL, Orthofer R, Lamuela-Raventós RM. "Analysis of total phenols and other oxidation substrates and antioxidants by means of folin-ciocalteu reagent," Methods Enzymol.(1999); 299: 152-178.

16. Miliauskas G, Venskutonis PR, van Beek TA. "Screening of radical scavenging activity of some medicinal and aromatic plant extracts," Food Chem.(2004); 85 (2):231-237.

17. Vaz JA, Barros L, Martins A, Santos-Buelga C, Vasconcelos MH, Ferreira ICFR. "Chemical composition of wild edible mushrooms and antioxidant properties of their water soluble polysaccharidic and ethanolic fractions," Food Chem. (2011);126 (2): 610-616.

18. Riyanti S, Suganda AG, Sukandar EY. "Dipeptidyl peptidase-IV inhibitory activity of some Indonesian medicinal plants.," Asian J. Pharm. Clin. (2016); 9(2): 375-377.

19. Shiban MS, Al-Otaibi MM, Al-Zoreky NS. "Antioxidant Activity of Pomegranate (Punica granatum L.) Fruit Peels," Food Nutr. Sci. (2012); 3: 991-996.

20. Chaitanya V, Narayan NP, Kumar S, Chowdary KPR. J. Glob. Trends Pharm. Sci. (2014); 5 (1):13561360 . 